\title{
Histology of the lens in the Weill-Marchesani syndrome
}

\author{
Hisako Fujiwara, Yasushi Takigawa, Shinya Ueno, Kanshi Okuda
}

\begin{abstract}
The Weill-Marchesani syndrome is a rare systemic connective tissue disease characterised by small stature, brachydactyly, ectopia lentis, and spherophakia. Three siblings with typical manifestations of this syndrome were reported. The ophthalmological findings in all these cases were spherophakia, severe myopia, a shallow anterior chamber, and narrow angle glaucoma. Two cases underwent laser iridotomy and drug treatment. In the third case the lens was removed from the eye because of injury, and this lens was examined by light and electron microscopy.
\end{abstract}

The Weill-Marchesani syndrome was first reported in one patient with brachydactyly and microspherophakia by Weill ${ }^{1}$ in 1932 during research on the Marfan syndrome. In 1936 Marchesani ${ }^{2}$ reported four cases with brachycephaly, small stature, brachydactyly, and microspherophakia considered to have this syndrome.

The Weill-Marchesani syndrome is characterised by dystrophia mesodermalis hyperplasia in contrast to the Marfan syndrome, in which dystrophia mesodermalis hypoplasia is present. ${ }^{3}$ The Weill-Marchesani and Marfan syndromes therefore appear to be mirror images of each other. ${ }^{4}$

In this syndrome treatment of the glaucoma is the main problem.

Three siblings with typical manifestations of the syndrome are reported on here. Two underwent laser iridotomy and drug treatment to control the intraocular pressure. In the third case the lens had been removed from the eye because of injury, and this lens was examined histologically.

Department of

Ophthalmology,

Kawasaki Hospital,

Kawasaki Medical

School

H Fujiwara

Y Takigawa

Department of

Ophthalmology,

Tsuyama Central

Hospital

$S$ Ueno

Department of

Ophthalmology, National

Ophthalmology, National

K Okuda

Correspondence to:

Dr Hisako Fujiwara

Department of

Department of

Ophthalmology, Kawasaki

School, 2-1-80 Nakasange

Okatama 700, Japan.

Accepted for publication

26 April 1990

\section{Case reports}

Case 1, proband, a 13-year-old female (Figs 1, 2) and case 2 eldest brother of case 1, 30-year-old male (Fig 3) were typical cases, successfully treated by laser iridotomy.

Case 3 was a 20-year-old male, elder brother of case 1 . Because his sister and brother had been treated for glaucoma he came to the authors' department for a detailed examination. His visual acuity was $20 / 20$ with $-11 \mathrm{D}$ in the right eye and $24 / 20$ with $-14 \mathrm{D}$ in the left eye. The anterior chamber was shallow and the angle was narrow. The intraocular pressure was $14 \mathrm{mmHg}$ in the right eye and $16 \mathrm{mmHg}$ in the left.

At 1800 on 3 June 1988 a piece of wood struck him in the right eye while he was cutting down a tree with an electric saw: He was immediately examined by a local physician and underwent an

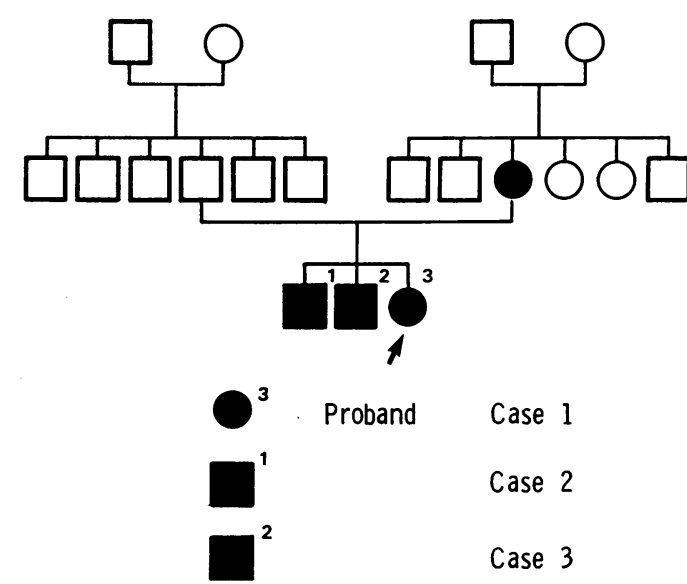

Figure 1 Family tree of patients reported on here.

emergency operation because of a ruptured right eyeball. The lens was easily removed from the eye during operation. The details of Zinn's zonule were not clear. The lens capsule was not ruptured and spherophakia was observed. The equatorial diameter was rather small at $7 \mathrm{~mm}$, and the sagittal diameter was longer than normal. There was some protrusion in the pupillary area (Fig 4).

The lens was immediately fixed in neutral formalin.

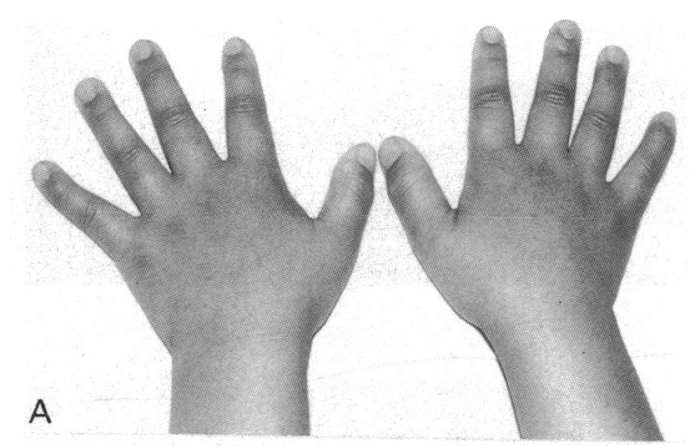




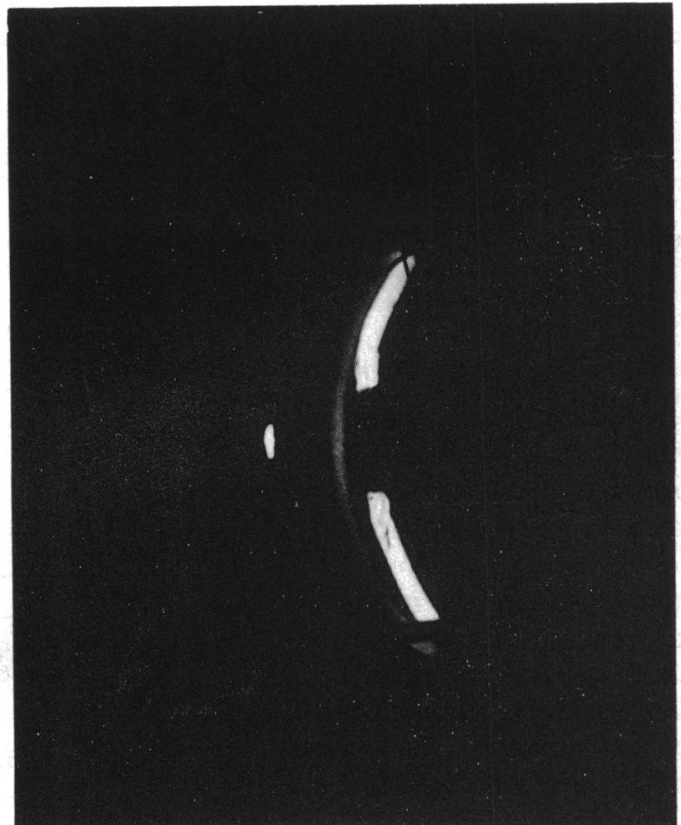

Figure 3 Slit-lamp view of the elder brother of the proband showing an extremely shallow anterior chamber.

\section{LIGHT MICROSCOPY}

The anterior capsule appeared to be almost normal. The epithelial cells were irregularly
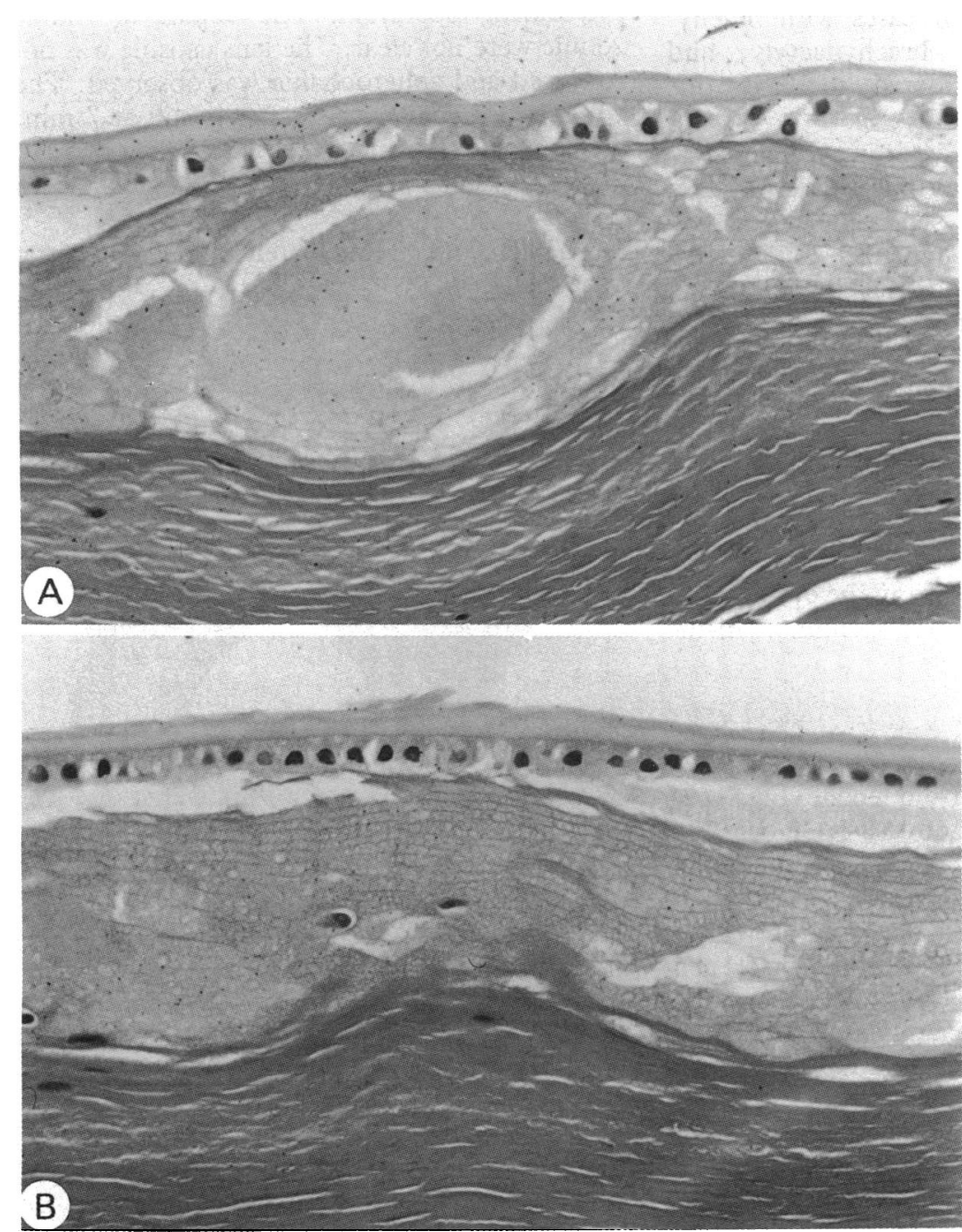

Figure 5 Light microscopic picture. A: The epithelial cells are irregularly shaped. Many of the cortical fibres are liquefied, forming homogeneous amorphous masses. (Haematoxylin and eosin, $\times 170$.) B: The nuclear lens fibers are strongly eosinophilic and well oriented. (Haematoxylin and eosin, $\times 170$.)
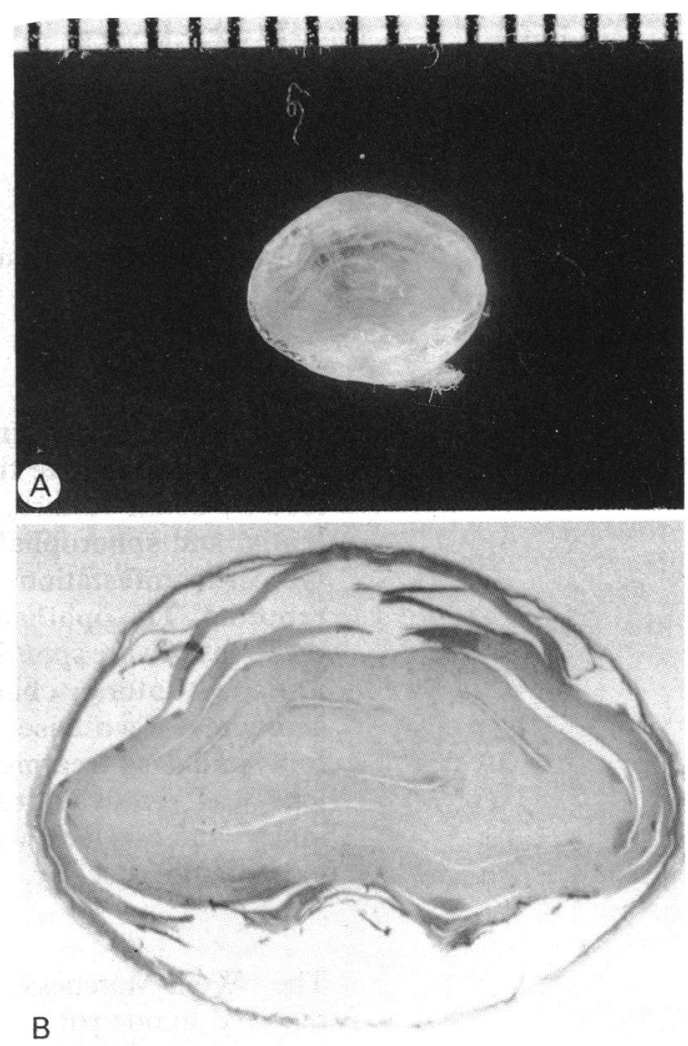

Figure 4 Extracted lens of the brother of the proband; small in size and round in shape. B: Appearance of the extracted lens. Large sagittal diameter and projection into the pupillary space are seen.

shaped and some of their nuclei appeared pyknotic. Many vacuoles were seen between epithelial cells. Many of the cortical fibres had liquefied, forming homogeneous amorphous masses. The nuclear lens fibres were strongly eosinophilic and well orientated (Fig 5).

The anterior capsule stained strongly positive with periodic acid Schieff. A few cortical lens fibre nuclei remained in the deeper area (Fig 6).

The posterior capsule was thin. The subcapsular posterior cortex was totally liquefied, and homogeneous proteinaceous masses filled with subcapsular area (Fig 7).

\section{ELECTRON MICROSCOPY}

The anterior capsule was homogeneous and its anterior and posterior surfaces were smooth. The epithelial cells were mostly cuboid. The nucleus was round. The nuclear envelope was smooth, with many nuclear pores. The euchromatin was finely granular and evenly distributed throughout the nucleus, and the heterochromatin appeared as many dense, irregularly formed aggregates. In some degenerating cells nuclear envelopes were lost in some regions, and aggregates of heterochromatin had decreased in number. The cytoplasm contained small mitochondria, rough-surfaced endoplasmic reticulum, and single or aggregated ribosomes. Many vacuoles of different sizes were found throughout the cytoplasm. Adjacent cells often had deep interdigitations and showed many intercellular irregular gaps with fine granular debris. The subepithelial lens fibres were completely degenerated and appeared as evenly distributed granular masses (Figs 7, 8, 9). 

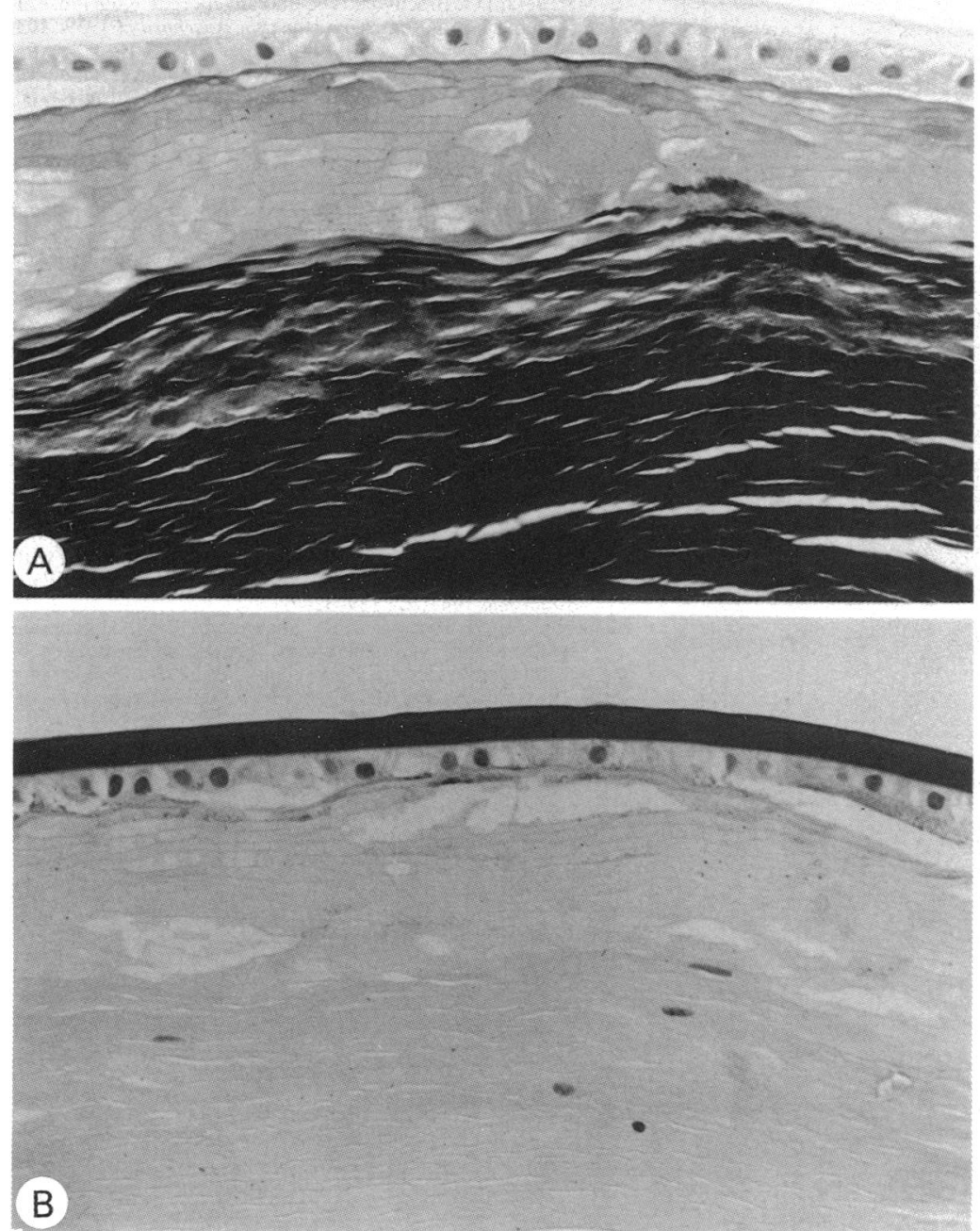

Figure 6 Light microscopic findings. A: Some of the cortical fibres are liquefied and a form homogeneous amorphous masses. The nuclear fibres are strongly eosinophilic. (Masson's trichrome, $\times 170$. $)$ B. The anterior capsule is strongly PAS-positive. $(P A S, \times 170$.

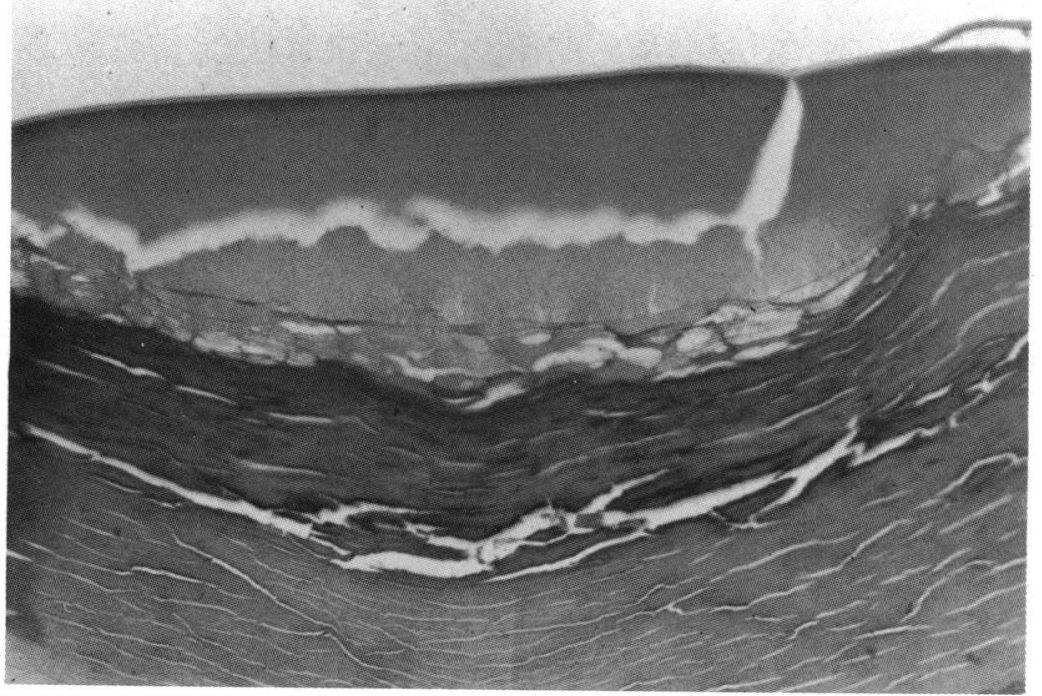

Figure 7 Posterior portion of the lens. The subcapsular posterior cortex is totally liquefied. (Masson's trichrome, $\times 170$.)

\section{Discussion}

The ophthalmological complications of the Marchesani syndrome include microspherophakia associated with ectopia lentis, lens myopia, and secondary glaucoma. The lens is small and spherical with an equatorial diameter of $6.75 \mathrm{~mm}$ on the average and a sagittal diameter $25 \%$ larger than normal. ${ }^{4}$ The angle becomes narrow because of the shallow anterior chamber caused by the spherophakia and the forward movement of the lens, but there have also been cases of congenital angular abnormalities. ${ }^{56}$

Peripheral iridectomy ${ }^{7-9}$ is an operative technique for pupillary block glaucoma in this syndrome, but recently laser iridotomy has appeared as a safe method, with few complications. ${ }^{10}$ Lensectomy is difficult to perform in these cases, and complications are apt to arise. However, it has been reported that no complications occur when irrigation-aspiration is performed with anterior capsulotomy by YAG laser. ${ }^{11}$

To maintain visual acuity an early diagnosis and surgery before the visual acuity decreases are necessary. ${ }^{12}$ In the diagnosis of visual disturbances in children, cases have been reported in which attacks of acute glaucoma occurred from cyclopentolate eyedrops, or the glaucoma did not improve owing to pilocarpine eyedrops. ${ }^{13}$

Genetically this syndrome often involves autosomal recessive inheritance, and there have been cases where it appears in a father and his sons and daughters ${ }^{14}$ and in a mother and sons. ${ }^{15}$ In our report the syndrome appeared in a mother, her two sons, and a daughter. This case was considered to be one of autosomal dominant inheritance.

In the present study we obtained a lens removed from the eye owing to an accidental injury, and it was examined histologically. In previous reports there have been records only of the shape, size, and weight of the lens but no histological findings. It has been suggested that microspherophakia is caused by growth of the lens ceasing congenitally when the fetus is 5-6 months old, so that the lens retains it initial shape. ${ }^{16}$ In the lens we obtained there was marked degeneration of the epithelial cells of the lens and marked liquefaction and destruction of the subcapsular cortical fibres in the anterior and posterior poles in addition to microspherophakia. These findings indicated a lens with a complicated cataract. ${ }^{17}$ However, there was no hypertrophy of the capsule such as that seen in cataract lenses complicated with iriditis.

Degeneration and necrosis of the epithelial cells of the lens are caused by various factors including aging, inflammation, trauma, and surgery. ${ }^{18}$ Destruction of the cortical fibres is a common histological change seen in lenses with senile cortical cataracts; in the present case of Weill-Marchesani syndrome it was considerable.

These changes appear to be due to physical and mechanical factors, because the lens is highly movable and often in contact with the iris, especially in association with long term irritation in the pupillary area in cases of microspherophakia. However, other biochemical changes within the lens cannot be ruled out. 

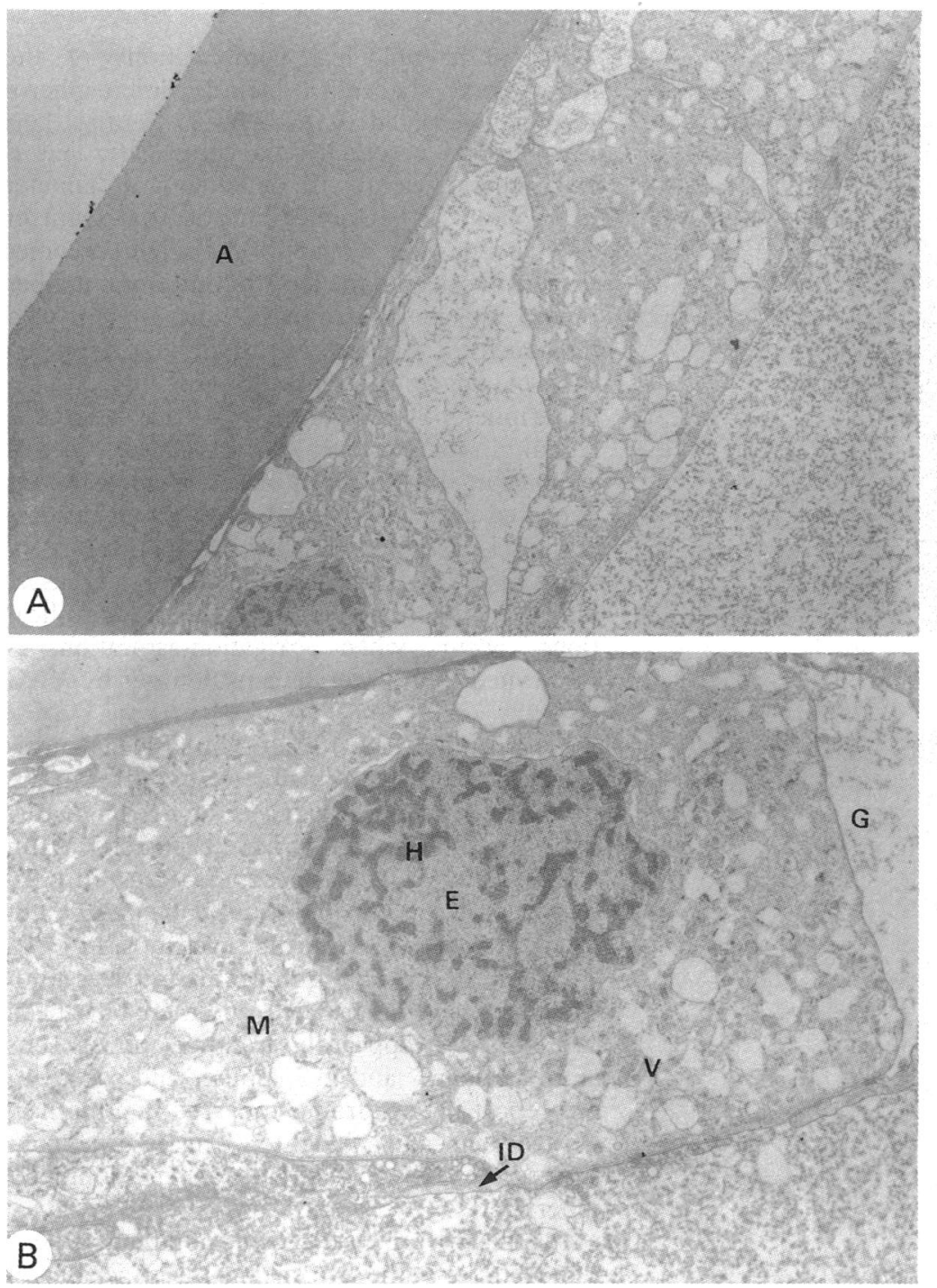

Figure 8 Electron microscopic findings of the anterior lens capsule. A: The anterior capsule $(A)$ is homogeneous, and its anterior and posterior surfaces are smooth. $(\times 2500$.$) B: Lens$ epithelial cell. The nucleus of the epithelial cell is round. The euchromatin $(E)$ is finely granular. The heterochromatin $(H)$ appears as aggregates. The cytoplasm contains small mitochondria $(M)$ and many vacuoles $(V)$. Adjacent cells have deep interdigitations $(I D)$ and show many intercellular irregular gaps $(G) .(\times 4200$.

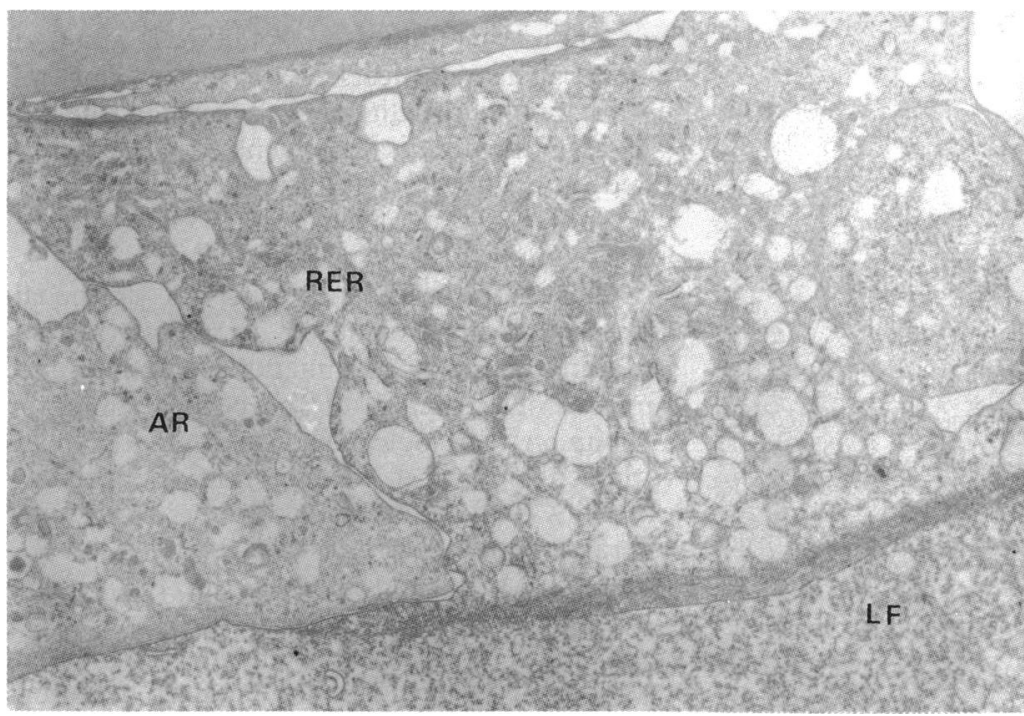

Figure 9 Lens epithelial cell and lens fibre. The cytoplasm contains rough surfaced endoplasmic reticulum $(R E R)$ and single or aggregated ribosomes $(A R)$. The subepithelial lens fibres $(L F)$ are degenerated and appear as evenly distributed granular masses. $(\times 4200)$.
1 Weill G. Ectopie des crystallins et malformations générales. Ann Oculist 1932; 169: 21-44.

2 Marchesani O. Brachydaktylie und angeborene Kugellinse als Systemerk-rankung. Klin Monatsbl Angenheilkd 1939: 103:

3 Jones RF. The syndrome of Marchesani. Br $\mathcal{J}$ Ophthalmol 1961; 45: 377-81.

4 McGavic JS. Weill-Marchesani syndrome. Am $\mathcal{F}$ Ophthalmol 1966; 62: 820-3

5 Dodo T. The spherophakia-brachymorphia syndrome. Nippon Ganka Gakkai Zasshi 1857; 61: 795-802.

6 Feiler-Obryv, Stein R, Godei V. Marchesani's syndrome and chamber angle anomalies. Am f Ophthalmol 1968; 65: 862-6.

7 Ritch R, Wand $M$. Treatment of the Weile-Marchesani syndrome. Ann Ophthalmol 1981; 13: 665-7.

8 Levy J, Anderson PE. Marchesani's syndrome. Br $\mathcal{F}$ Ophthalmol 1961; 45: 223-6.

9 Willi M, Kut L, Cotlier E. Pupillary block glaucoma in the Marchesani syndrome. Arch Ophthalmol 1973; 90: 504-8.

10 Ritch R, Podos SM. Argon laser treatment of angle-closure glaucoma. Perspect Ophthalmol 1980; 4: 129-38.

11 Woodward PM. Anterior capsulotomy of dislocated lenses in Marchesani syndrome. $f$ Am Intraocul Implant Soc 1984; 10: Marches.

12 Jensen AD, Cross HE. Ocular complications in the WeillMarchesani syndrome. Am F Ophthalmol 1974; 77: 261-9.

13 Wright KW, Chrousos GA. Weill-Marchesani syndrome with bilateral angle-closure glaucoma. $\mathcal{f}$ Pediatr Ophthalmol Strabismus 1985; 22: 129-32.

14 Gorlin RJ, L'Heureux PR, Shapiro I. Weill-Marchesani syndrome in two generations: genetic heterogeneity of pseudodominance. F Pediatr Ophthalmol 1974; 11: 139-44.

15 Young ID, Fielder AR, Casey TA. Weill-Marchesani syndrome in mother and son. Clin Genet 1986: 30: 475-80.

16 Mullaney J. Normal development and developmental anomalies of the eye. In Garner A, Klintworth GK, eds. Pathology of ocular disease. New York: Dekker, 1982: 443522.

17 Fujinaga Y, Matsunage H. Cataract 40-47. Tokyo: Kanehara Shuppan, 1987.

18 Klintworth GK, Garner A. The cause, types and morphology of cataracts. In: Garner A, Klintworth G, eds. Pathology of ocular disease. New York: Dekker, 1982: 1223-72. 